\title{
Creep behavior of dissimilar metal weld joints between P91 and AISI 304
}

\author{
Javed Akram ${ }^{1}$, Prasad Rao Kalvala ${ }^{1 *}$, Mano Misra ${ }^{1}$, Indrajit Charit ${ }^{2}$ \\ ${ }^{1}$ Dept. of Metallurgical Engineering, University of Utah, Salt Lake City, UT 84112 \\ ${ }^{2}$ Dept. of Chemical and Materials Engineering, University of Idaho, Moscow, ID 83844 \\ * Corresponding Author: Email: Prasad.Kalvala@utah.edu
}

\begin{abstract}
Dissimilar welds between ferritic creep-resistant steels and austenitic stainless steels in power plant service are known to fail prematurely due to a large difference in their thermal coefficient of expansion. To address this problem, in the current work, modified 9Cr-1Mo steel (P91) and austenitic stainless steel (AISI 304) transition joints were produced using friction welding employing three interlayers: Inconel 625, Inconel 600 , and Inconel $800 \mathrm{H}$. These interlayers were friction welded one over another on P91 alloy, which was finally friction welded to AISI 304. The joints produced with single and three interlayers were subjected to creep rupture tests at different temperatures and stress levels. The creep test results demonstrated that the proposed approach can help realize striking improvements in creep performance of P91/AISI 304 dissimilar metal welds. Further, analysis of creep resulted in a stress exponent $(n)$ of 3 by incorporating the concept of threshold stress which suggested the creep deformation mechanism to be viscous glide due to solute drag. Creep rupture data was also analyzed using MonkmanGrant relationship and creep damage tolerance factor $(\lambda)$. Results indicated that the damage mechanism is due to cavity growth by the combined effect of power law and diffusion creep.
\end{abstract}

Keywords: Dissimilar metal welding, Weld transition joint, P91 (Modified 9Cr-1Mo) steel, Austenitic stainless steel, Friction welding, Creep deformation mechanism. 


\section{Introduction}

The need for increasing steam temperatures to enhance thermal efficiencies led to the development of a variety of Cr-Mo steels. Burnard et al. [1] highlighted the need to improve thermal plant efficiencies. For example, current plants operating with steam temperature of $810 \mathrm{~K}$ have thermal efficiencies of around $35 \%$ and by increasing the steam temperature to $873 \mathrm{~K}$, the efficiencies of these plants could rise to around $42 \%$. This increase in thermal efficiency significantly reduces fuel consumption and environmental impact [1]. Therefore, high efficiency pulverized coal power plants capable of operating at steam pressures and temperatures much higher than possible today are under development to provide relatively low cost power with much less pollution [2,3]. High Cr ferritic-martensitic steels such as P91 and P92 provide the higher creep rupture strengths required for the higher steam temperatures [4]. Ennis and Czyrska-Filemonowicz found that for the same design conditions, the rupture strength of P91 and P92 was found to be higher compared to conventional Cr-Mo steels and close to austenitic stainless steels [5]. However, steam oxidation resistance is the drawback of P91/P92 steels limiting the operating temperature of P91 to $883 \mathrm{~K}$ and P92 to $893 \mathrm{~K}$ [4]. For boiler super heater tubes experiencing $903 \mathrm{~K}$, austenitic stainless steels such as AISI $304 \mathrm{H}, 316$ or $347 \mathrm{H}$ steels are used. These heater tubes have to be joined to steam headers made of P91. Hence, dissimilar, multi-material welding becomes necessary. Among the thousands of tube joints in a typical boiler, many are these types of dissimilar weld joints.

Though dissimilar welding has been practiced for many high temperature tubular applications, failures have been reported in these welds [6,7]. Laha et al. [7] reported 
inferior stress rupture properties of dissimilar welds of Cr-Mo steels with austenitic stainless steels compared to the base metal counterparts [7]. The main reasons cited for these failures are the mismatch between the coefficients of thermal expansion (CTE) between ferritic and austenitic stainless steel [6-9] and carbon migration from ferritic to austenitic steel $[6,8-12]$. To help reduce the carbon diffusion from ferritic to austenitic side, nickel based fillers are used instead of austenitic filler $[8,10,13]$. In terms of CTE, ferritic steels exhibit an average linear CTE of $13.2 \times 10^{-6} / \mathrm{K}$, while austenitic stainless steels exhibit $18.0 \times 10^{-6} / \mathrm{K}[14,15]$ in the temperature range of 294-873 K. William [15] suggested that at elevated temperature, P91 will try to constrain the stainless steel weld from expanding because of its lower CTE which results in build-up of large local tensile stresses at the interface and leads to failure of the joint [15]. Lee et al. (2007) have adopted few innovative methods to have a transition in CTE in fusion welds. These include using filler metals with an intermediate CTE or using an alloy with a CTE intermediate between two metals [16]. Though these modifications helped extend the life of weldment, they did not provide a permanent solution to this kind of a technically challenging problem. Several failures were reported to occur at the weld joint interfaces made with Ni-based filler materials [17-20]. Unfortunately, selection of a nickel-base filler material may not provide a fully satisfactory solution if the CTE difference between the two base metals is very significant or when the service conditions are demanding. More importantly, in some cases, a filler metal with an intermediate CTE along with all the other desirable qualities/properties may not even exist. Overall, there is a need to develop superior/alternative strategies for dealing with the problem of CTE mismatch in dissimilar welding. 
It is well-known that solid-state welding processes are better suited for joining dissimilar metals. When the issue is mainly CTE mismatch, solid-state welding processes such as rotary friction welding help manage the problem effectively because of the following reasons: Firstly, friction welding does not involve melting and the process is much more benign compared to fusion welding. This significantly widens the choice of interlayer materials. Secondly, with friction welding, it is relatively easy to employ multiple interlayers to ensure a smoother change in CTE between the two base metals, leading to better performing joints. The idea of friction welding between dissimilar metals with multiple interlayers can be advantageously utilized specifically for producing transition joints (or joining adaptors) for on-site fusion welding of ferritic creep-resistant steels to austenitic stainless steels in tube or pipe form, a major requirement in advanced power plants. To demonstrate the concept in the current work, friction welding of modified 9Cr-1Mo steel (P91) and austenitic stainless steel AISI 304 was attempted employing three commercial nickel-based alloys as interlayer materials, viz., Inconel 625, Inconel 600, and Inconel 800. These three interlayer materials were chosen based on their CTE values ((Inconel $625\left(14.40 \times 10^{-6} / \mathrm{K}\right)$, Inconel $600\left(15.30 \times 10^{-6} / \mathrm{K}\right)$ and Inconel $\left.800\left(16.02 \times 10^{-6} / \mathrm{K}\right)\right)$ to ensure that the change in CTE from 9Cr-1Mo side $\left(13.18 \times 10^{-}\right.$ $\left.{ }^{6} / \mathrm{K}\right)$ to AISI $304\left(18.0 \times 10^{-6} / \mathrm{K}\right)$ is very gradual.

In this study, the work is focused on comparison of creep behavior between single interlayer welds developed with Inconel 600 (P91/IN600/AISI304) and three interlayer welds developed with Inconel 625, Inconel 600, and Inconel $800 \mathrm{H}$ (P91/IN625/IN600/IN800H/AISI304). The selection of Inconel 600 for a single interlayer weld for this study is based on CTE similiarity with Inconel 82 which is convetionally 
used with fusion welding processes. CTE of Inconel 82, and Alloy 600 is quite similar [21]. Furthermore, the present work deals with analyzing the creep behavior, creep rupture life based on Monkman-Grant approach, and associated creep mechanisms in weld joints using thresold stress concept. To the best of our knowledge, no such creep deformation mechanism is reported in literature for the dissimilar weld transition joints.

\section{Experimental details}

\subsection{Materials}

The chemical composition of materials used (referred as base metals) in this study are listed in Table 1. P91 steel rods with diameter of $25.4 \mathrm{~mm}$ were normalized at 1353 $\mathrm{K}$ for $1 \mathrm{~h}$ and tempered at $1033 \mathrm{~K}$ for $2 \mathrm{~h}$. Circular rods of IN 625, IN 600, IN 800H, and AISI 304, $25.4 \mathrm{~mm}$ diameter were received in the hot rolled and annealed condition.

Table 1 Chemical compositon of base materials.

\begin{tabular}{|l|l|}
\hline Material & Composition (in wt.\%) \\
\hline P91 & $\begin{array}{l}0.12 \% \mathrm{C}, 9.23 \% \mathrm{Cr}, 1.14 \% \mathrm{Mo}, 0.30 \% \mathrm{Ni}, 0.30 \% \mathrm{Si}, 0.38 \% \mathrm{Mn}, 0.21 \% \mathrm{~V}, \text { and } \\
\text { Balance Fe }\end{array}$ \\
\hline IN 625 & $\begin{array}{l}0.03 \% \mathrm{C}, 22.00 \% \mathrm{Cr}, 0.10 \% \mathrm{Co}, 8.70 \% \mathrm{Mo}, 3.60 \% \mathrm{Nb}+\mathrm{Ta}, 0.20 \% \mathrm{Ti}, \\
3.90 \% \mathrm{Fe}, \text { and Balance Ni }\end{array}$ \\
\hline IN600 & $\begin{array}{l}0.05 \% \mathrm{C}, 16.50 \% \mathrm{Cr}, 9.00 \% \mathrm{Fe}, 0.30 \% \mathrm{Ti}, 0.04 \% \mathrm{Co}, 0.03 \% \mathrm{Nb}+\mathrm{Ta}, \text { and } \\
\text { Balance Ni }\end{array}$ \\
\hline IN800H & $0.07 \% \mathrm{C}, 20.40 \% \mathrm{Cr}, 45.40 \% \mathrm{Fe}, 0.51 \% \mathrm{Ti}$, and Balance Ni \\
\hline AISI & $0.08 \% \mathrm{C}, 18.60 \% \mathrm{Cr}, 8.20 \% \mathrm{Ni}, 1.00 \% \mathrm{Mn}, 0.30 \mathrm{Si}$, and Balance Fe \\
\hline 304 & \\
\hline
\end{tabular}


2.2. Welding procedure and post weld heat treatment

Rotary friction welding machine was used to develop transition joints. Following welding parameters were used: Friction pressure of $160 \mathrm{MPa}$; upset pressure of $280 \mathrm{MPa}$; rotational speed of $1500 \mathrm{rpm}$; and burn-off length (amount of material which will be spend during welding) of $5 \mathrm{~mm}$. Figure 1 illustrates the schematic of steps involved in making of P91/AISI 304 weld transition joints using rotary friction welding machine. To make the transition joint, first IN 625 rod was friction welded to P91 rod. IN 625 with 8 mm thick layer was cut and left on the P91 rod. Then IN625 rod was welded with IN 600. After welding, $3 \mathrm{~mm}$ thick IN625 was left as an interlayer (taking into account $5 \mathrm{~mm}$ burn-off length). IN 600 and IN800H interlayers were successively deposited in the same way and finally AISI 304 rod was friction welded to IN800H interlayer. The thickness of each interlayer in the final joint was $3 \mathrm{~mm}$. The weld transition joints were post-weld heat treated at $1023 \mathrm{~K}$ for $1 \mathrm{~h}$ followed by air cooling. The transition joints will further be referred as follows: (P91/IN600/AISI304) - single layer weld (SLW) and (P91/IN625/IN600/IN800H/AISI304) as three layer weld (3LW).

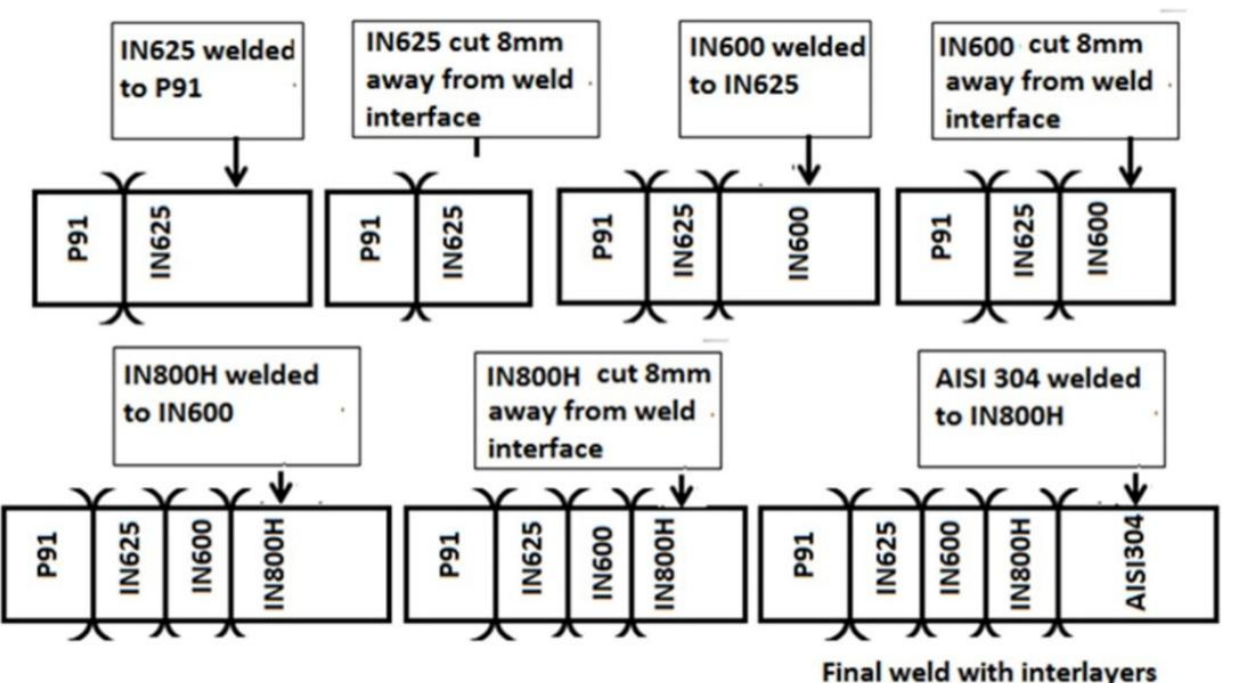

Figure 1 Stepwise illustration of transtion weld creation by friction welding 


\subsection{Microstructural characterization}

Microstructural analysis of all the base metals, as-welded and post weld heat treated samples was perfomed using optical microsope. Standard metallographic prodecure of hot mounting, grinding, and polishing were performed to prepare the sample up to the surface roughfness of $0.05 \mu \mathrm{m}$ followed by etching. Different etchants were used to characterize the microstrcuture. P91 steel was etched using Marble's reagent (50 $\mathrm{ml}$ distilled water $+50 \mathrm{ml}$ hydrochloric acid $+10 \mathrm{~g}$ copper sulphate). Inconel alloys were etched using Kalling reagent $\left(100 \mathrm{ml}\right.$ ethanol $\left.+100 \mathrm{ml} \mathrm{HCl}+5 \mathrm{~g} \mathrm{CuCl}_{2}\right)$. AISI 304 was electrolytically etched using oxalic acid solution $(10 \mathrm{~g}$ oxalic acid $+100 \mathrm{ml}$ water) employing a platinum electrode (voltage $6 \mathrm{~V}$, current density $1 \mathrm{~A} / \mathrm{cm}^{2}$, time 1-2 minutes). Detailed microstructural analysis was performed on P91 steel with scanning electron microscope (SEM). Field emission gun SEM equipped with energy dispersive spectroscopy (EDS) technique was used for this purpose. The EDS technique was used to study the relevant chemical characteristics of the fractured surface of the crept samples.

\subsection{Stress rupture testing}

Stress rupture test was performed using a canti-lever beam test set up with a 20:1 lever arm ratio. Tests were carried out at different temperatures between $823 \mathrm{~K}$ to $973 \mathrm{~K}$ and stresses between $75 \mathrm{MPa}$ to $250 \mathrm{MPa}$. Stress rupture tests were performed on post weld heat treated samples only. Figure 2 shows a typical welded and test specimen indicating dimensions. The specimens were extracted along axial direction keeping Inconel 600 as a center point in both SLW and 3LW. The gauge length $(15 \mathrm{~mm})$ consisted of five materials (P91, IN 625, IN 600, IN 800H, and AISI 304) in 3LW and three material (P91, IN 600, and AISI 304) in SLW having $3 \mathrm{~mm}$ thickness each. 
Maximum of eight sample were extracted from each welded rod after ensuring similar thickness of interlayer in each test specimen. Some of the tests were interrupted before final failure due to time constraint.

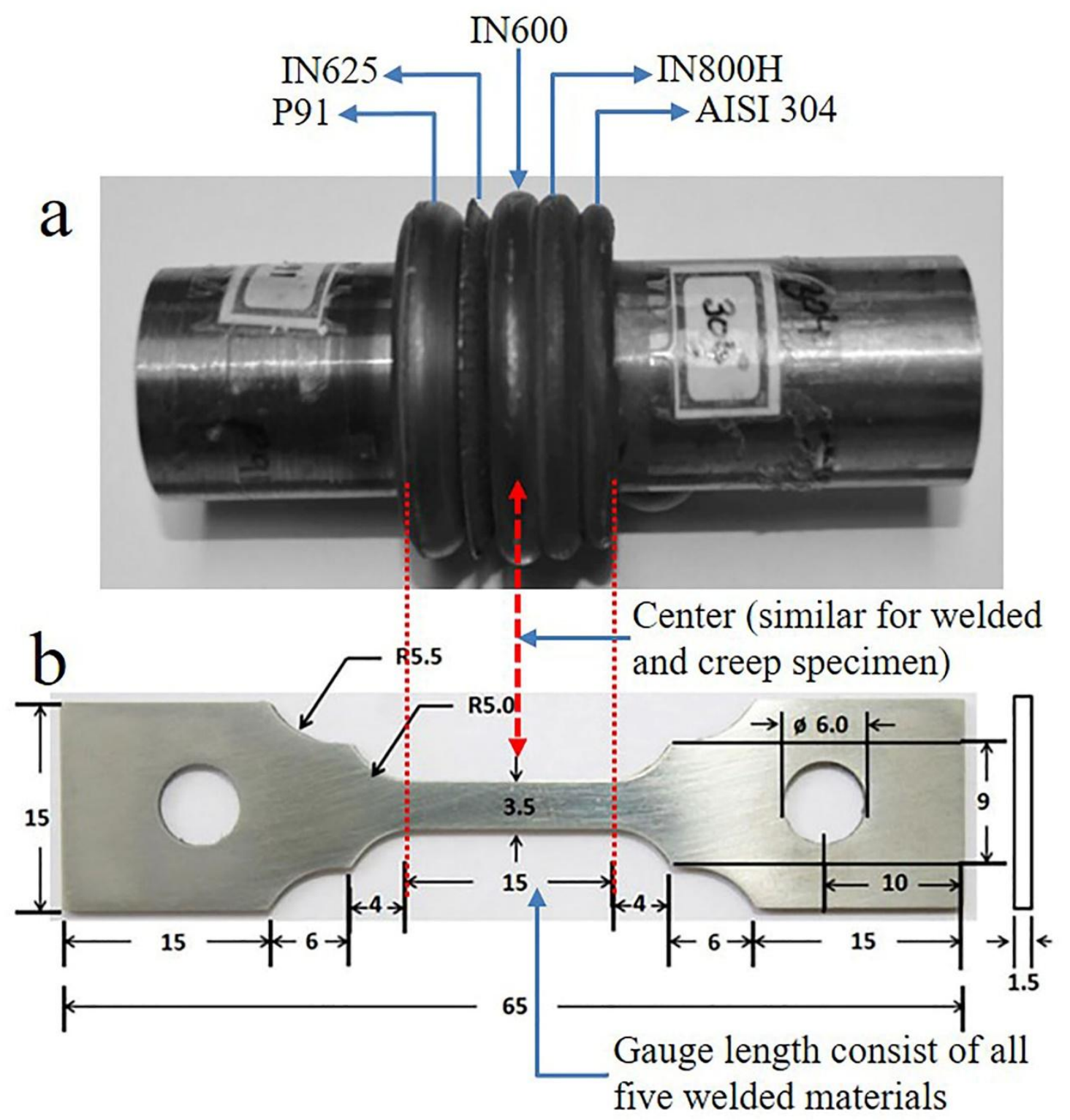

Figure 2 (a) friction welded sample (3LW) and (b) flat creep specimen cut along axial direction (all dimension in $\mathrm{mm}$ ). 


\section{Results and discussion}

\subsection{Microstructure of P91 base metal}

Figure 3a and $\mathbf{3 b}$ show the SEM pictures of modified 9Cr-1Mo (P91) steel in the normalized and tempered condition at lower and higher magnifications, respectively. Microstructure of normalized and tempered base material consisted of tempered martensite as shown in Figure 3a. Mechanisms by which these high alloy steels are strengthened include solution hardening, precepitiation or dispersion hardening, dislocation hardening, and boundary or sub-boundary hardening [22]. However, creep strength of this high alloy steels (P91) comes predominantly siginificantly from precipitation hardening in addition to other hardening mechanisms.
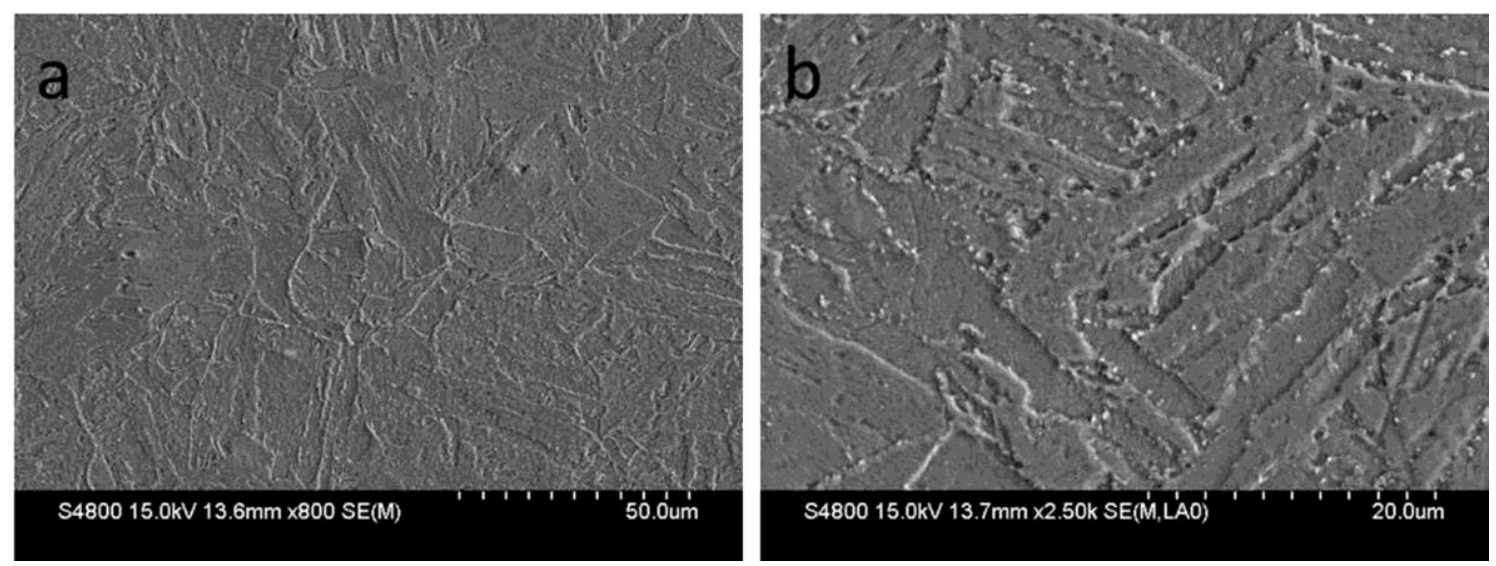

Figure 3 SEM micrographs (secondary electron images) showing microstructure of normalized and tempered P91 steel (a) lower (b) higher magnification.

Several types of carbonitrides and intermetallic compounds are present at the grain boundaries and in the matrix. Typical carbides and carbonitrides include $\mathrm{M}_{23} \mathrm{C}_{6}$, $\mathrm{M}_{6} \mathrm{C}, \mathrm{M}_{7} \mathrm{C}_{3}, \mathrm{MX}$, and $\mathrm{M}_{2} \mathrm{X}$, where $\mathrm{M}$ stands for metallic element such as $\mathrm{Cr}, \mathrm{Mo}, \mathrm{Nb}$, and $\mathrm{V}$ and $\mathrm{X}$ stands for carbon and nitrogen atoms. The volume percenage of $\mathrm{Cr}_{23} \mathrm{C}_{6}$ precipitates are almost $2 \%$ whereas MX type precipitates are close to $0.2 \%$ [22]. The size 
and shape of these two types of precipitates are also different: $\mathrm{M}_{23} \mathrm{C}_{6}$ carbides are present in the rod shape which are larger in size as compared to smaller, spherical MX-type precipitates [23]. Figure 3b shows the presense of carbides (white particles) at grain boundaries of lath martensite in a higher magnification picture of P91.

3.2. Stress rupture behavior: comparison between single and three layer welds

A typical creep curve consists of three stages: 1) primary, 2) seocndary, and 3) tertiary. In the primary stage, the creep rate decreases due to work hardening via dislocation multiplication and interaction. In the secondary (or steady state) creep stage, the creep rate is relatively constant due to balance between work hardening and recovery effect. Finally, in the tertiary stage, the creep rate increases rapidly because of cavities/voids start growing leading to final failure. In this study, all the creep curves showed three distinct regions: primary, secondary and tertiary regions as shown in Figure 4a. Three layer welds were compared with single layer welds (SLW). Figure 4a shows the comparision of creep curves between single layer weld (SLW) and three layer weld (3LW) tested at $873 \mathrm{~K} / 200 \mathrm{MPa}$ and $923 \mathrm{~K} / 125 \mathrm{MPa}$. Results showed improved creep life for three layer welds under both of these conditions. For example, the rupture life of single layer weld crept at $873 \mathrm{~K}$ and $200 \mathrm{MPa}$ was $15.2 \mathrm{~h}$, whereas three layer weld ruptured after $67.4 \mathrm{~h}$. Similarly, the rupture life for three layer weld crept at $923 \mathrm{~K}$ and $125 \mathrm{MPa}$ was 58 hours whereas for single layer weld, it was only 28 hours. Figure $4 \mathbf{b}$ shows the plot between creep rate and strain for 3LW and SLW tested at similar conditions. It is interesting to note that the behavior of all the tests are roughly similar irrespective of their failure time. 

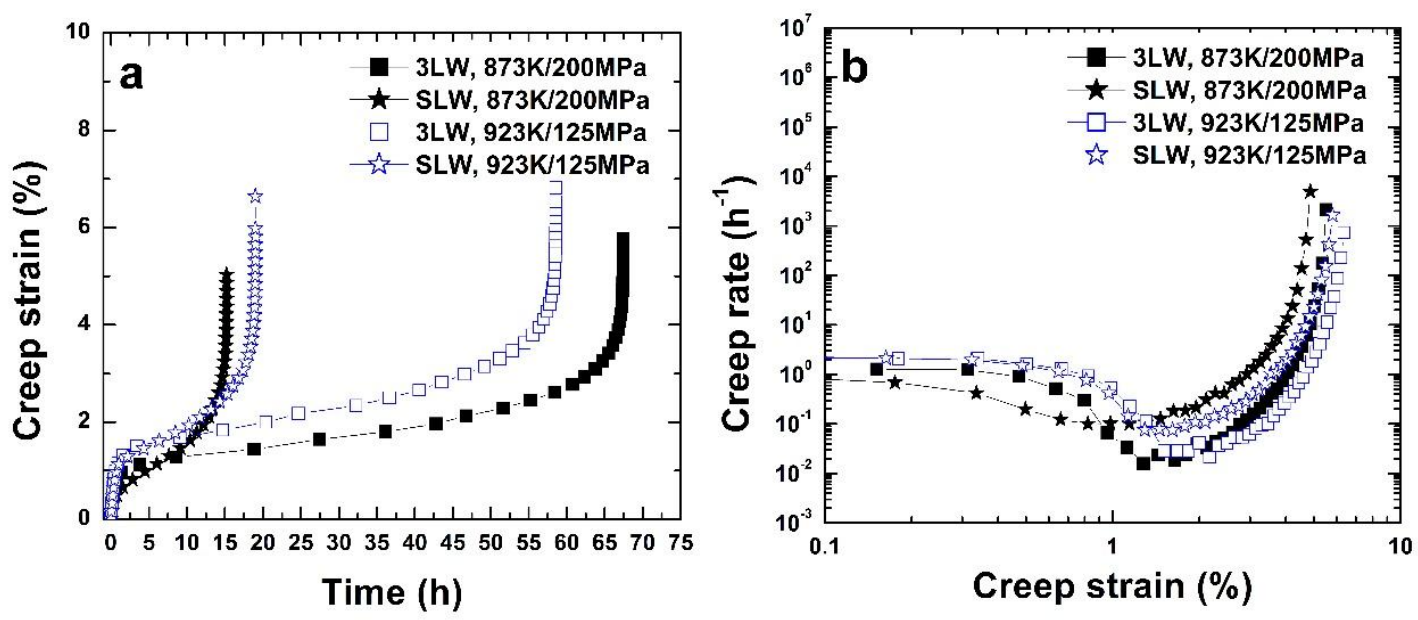

Figure 4 Plot between (a) creep strain vs time (b) creep rate vs strain for 3LW and SLW tested at different conditions.

Figure 5 is a plot between rupture time and stress of all the single layer and three layer welds. The graph compares the rupture time of single layer and three layer welds tested at different temperatures and stress levels. A limited number of single layer welds were tested for comparison purpose. It can be seen from Figure 5, irrespective of test temperatures and stress levels, three layer welds performed better than single layer welds.

Figure 6 shows the hardness profile of three and single layer weld crept at $923 \mathrm{~K}$ and $125 \mathrm{MPa}$. The failure location is located in the preexisting soft zone region and can be seen in hardness profile of three and single layer welds compared with PWHT sample $(1023 \mathrm{~K} / 1 \mathrm{hr})$. The failure location of all of the three and single layer welds were found to be in the preexisting soft zone which is around $2 \mathrm{~mm}$ away from the weld interface. The soft zones near the fracture tips exhibited white regions in the microstructures as shown in Figure 7. Figure 7a and Figure $\mathbf{7 b}$ are the microstructures of a three layer weld tested at $923 \mathrm{~K}$ and $125 \mathrm{MPa}$ at the interface and fracture tip, respectively. Figure 7c and Figure 7d are the microstructures of single layer weld tested at $973 \mathrm{~K}$ and $125 \mathrm{MPa}$ at 
interface and fracture tip, respectively. Both three and single layer welds showed a soft zone near the fracture tip as indicated by arrow marks in Figure $\mathbf{7 b}$ and Figure 7d. The interfacial microstructure of both three and single layer welds does not show any soft zone formation near the interface, as shown in Figure 7a and Figure 7c.

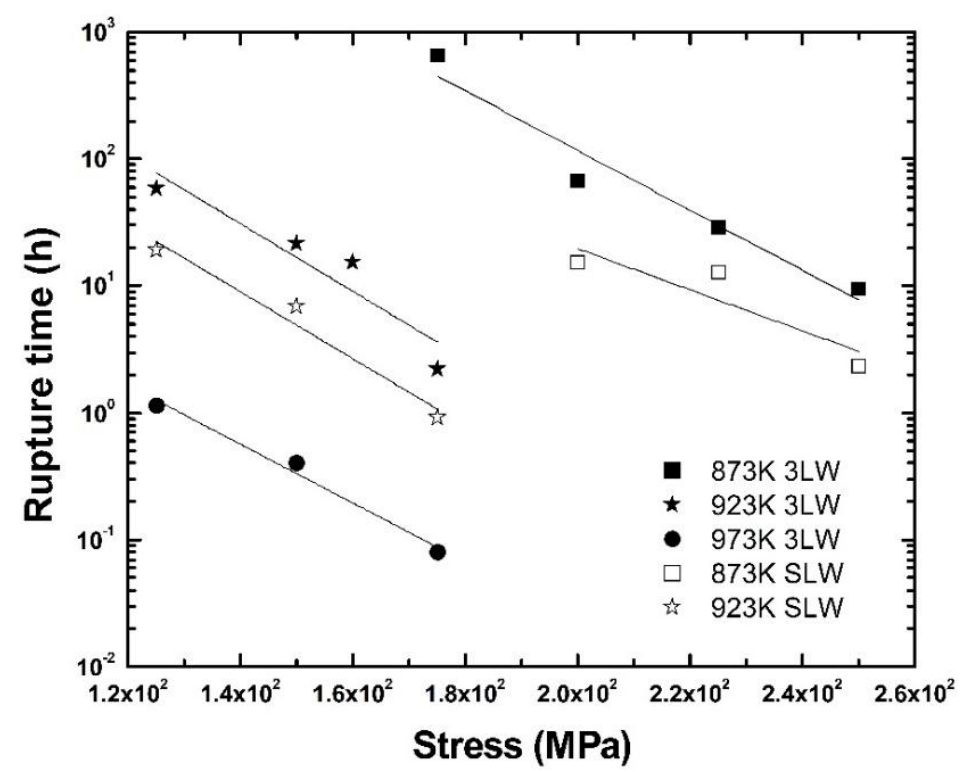

Figure 5 Plot between rupture time and stress for three layer weld and single layer weld at different temperatures and stress levels.

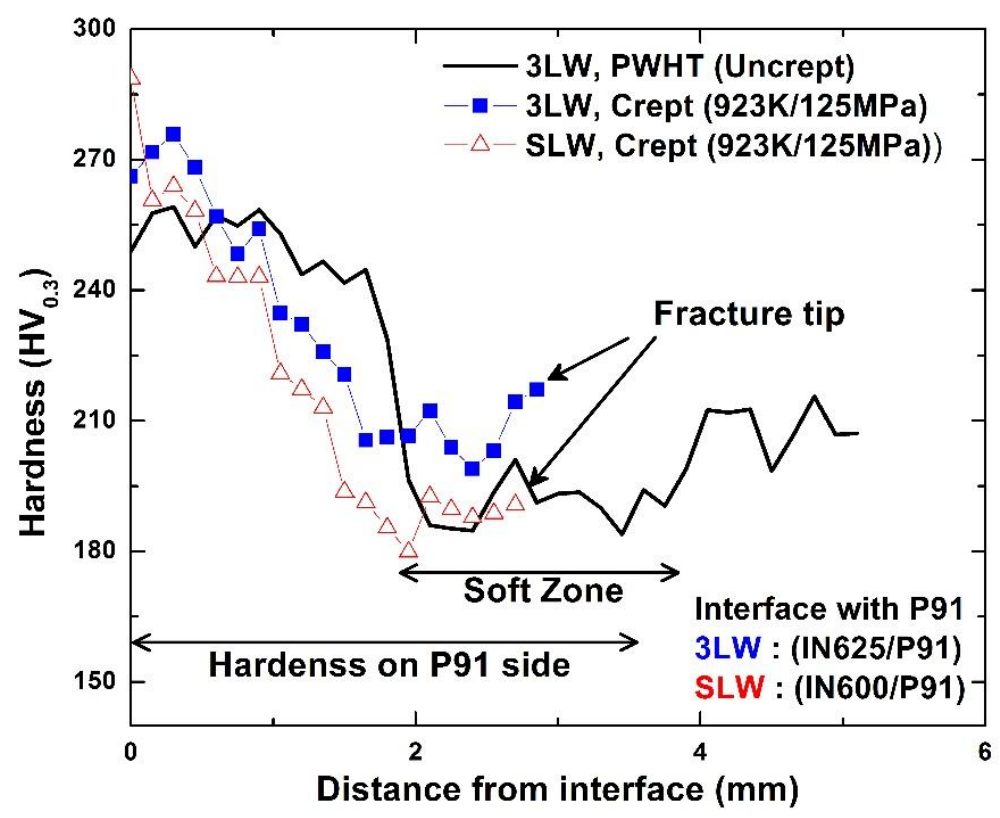

Figure 6 Hardness profile of three layer weld and and single layer weld crept at $923 \mathrm{~K}$ and $125 \mathrm{MPa}$. 
Both these welds showed similar microstructure, however three layer welds performed better than single layer weld. The only possible reason which would help increasing the life of three layer welds is gradient in coefficient of thermal expansion. It has been reported that the presence of inhomogeneous microstructure across the interface develop stress concentration and stress triaxiality which also promotes the failure of dissimilar weld joints [7]. Similarly, in the three and single layer welds apart from inhomogeneous microstructure across the weld interface, another factor which contributes to stress concentration is the mismatch in CTE value. In the single layer weld, a transition is provided but not as gradual as the three layer weld, therefore the increased rupture life of the three layer weld can be correlated to the more gradual transition in CTE value from austenitic to ferritic side.

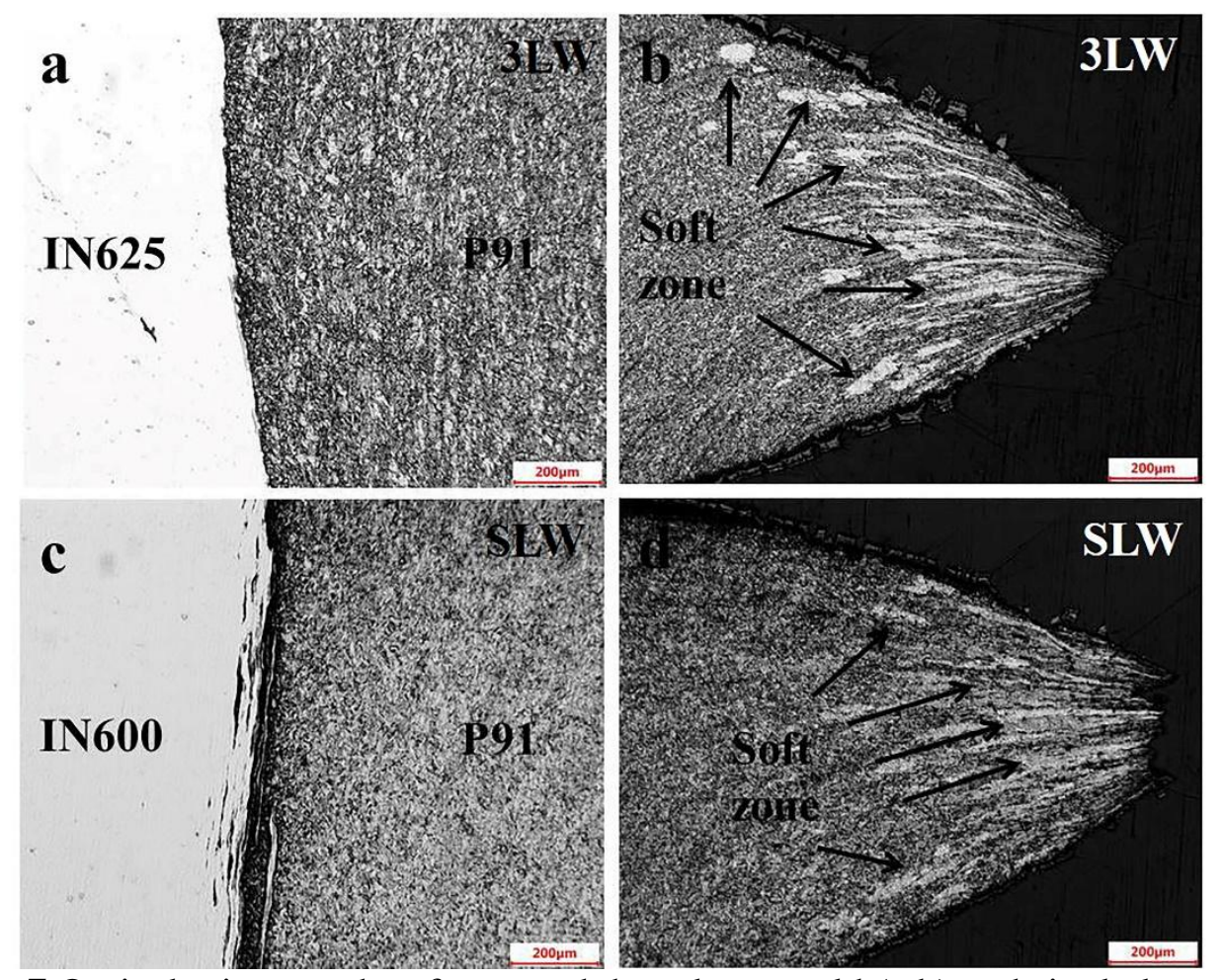

Figure 7 Optical micrographs of ruptured three layer weld (a,b) and single layer weld (c,d) tested at $923 \mathrm{~K}$ and $125 \mathrm{MPa}$. (a) interface between P91 and IN625 (b) fracture tip of three layer weld (c) interface between P91 and IN600 (d) fracture tip of single layer weld 


\subsection{Fractography of crept specimens}

Figure 8a and Figure 8b show the fractographs of the 3LW sample crept at 873 $\mathrm{K} / 175 \mathrm{MPa}$ and $873 \mathrm{~K} / 200 \mathrm{MPa}$ respectively. Both the fractured surfaces showed dimple patterns with multiple numbers of cavity and voids. The dimple pattern is a characteristic feature of transgranular mode of facture. The transgranular mode of fracture in $9 \mathrm{Cr}-1 \mathrm{Mo}$ steel was also reported by Shrestha et al. [24] and Choudhary et al. [25]. The size and number density of creep voids are different at different operating conditions; larger voids are observed at low applied stress (175 vs. $200 \mathrm{MPa}$ ). However, the density of creep voids is higher at higher stress. The higher density of creep voids is probably due to accelerated plastic deformation due to the high applied stress. On the other hand, the large size of voids can be attributed to a longer duration of the sample exposed to such elevated temperature (652 hr vs. $67 \mathrm{hr}$ ). Figure 8c and $\mathbf{8 d}$ show the cross-section area near the fractured tip, tested at a higher temperature and lower stresses (923 K at 125 and $150 \mathrm{MPa}$ ). A smaller cross section area is observed at the higher applied stress. Figure 9 shows the comparison of fracture strain and reduction in area at different temperatures and stresses. Increased reduction in area and true strain is observed with increased temperature and stress. Similar behavior is also reported by Shrestha et al. [24] in modified 9Cr-1Mo steel. Accelerated void formation, coalescence of microvoids, and plastic flow at high temperature and stress levels result in high percentage of area reduction and fracture strain. 

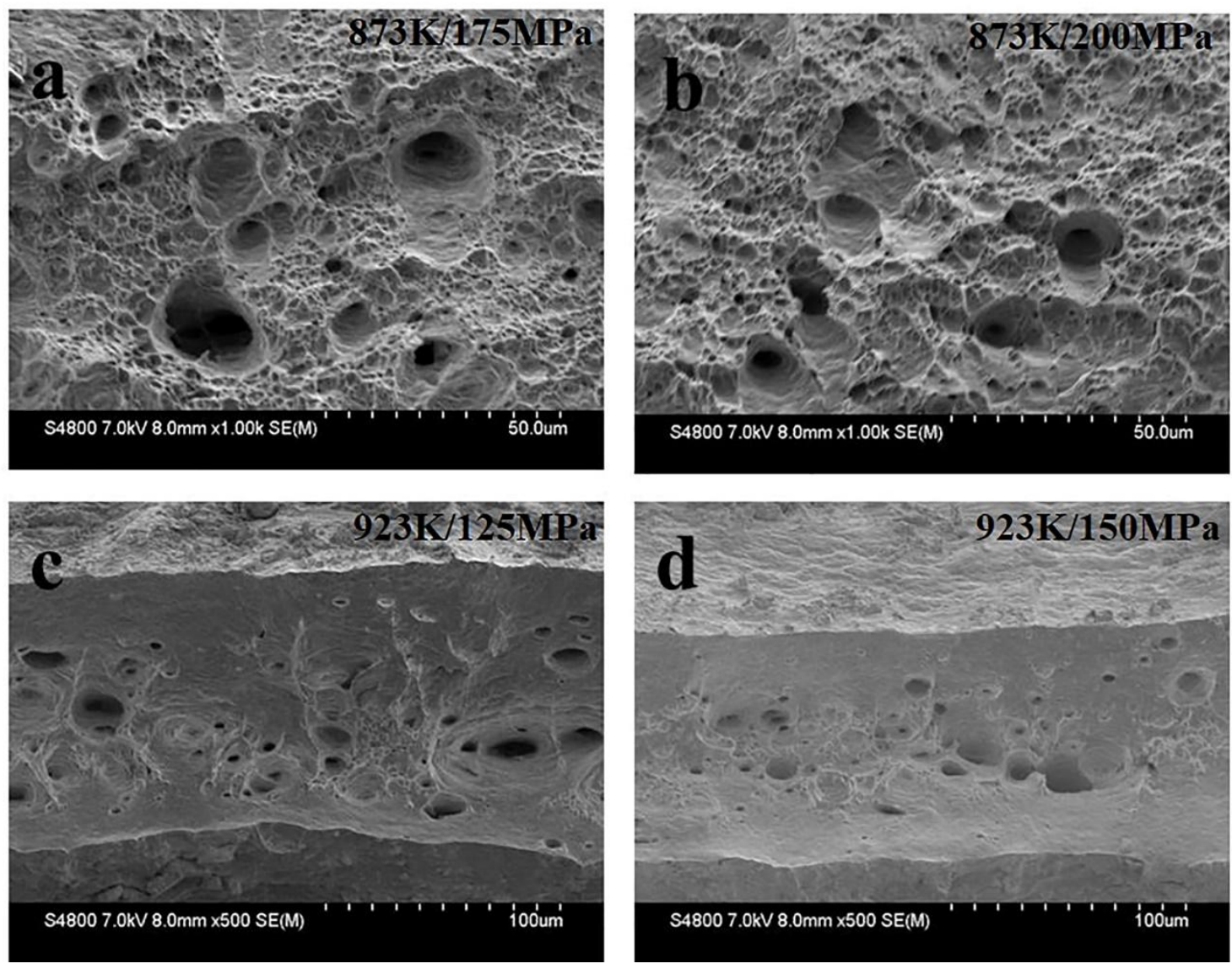

Figure 8 SEM micrograph (secondary electron images) of fractured surfaces of 3LW tested at: (a) $873 \mathrm{~K} / 175 \mathrm{MPa}$, (b) $873 \mathrm{~K} / 200 \mathrm{MPa}$, (c) $923 \mathrm{~K} / 125 \mathrm{MPa}$, and (d) $923 \mathrm{~K} / 150$ $\mathrm{MPa}$.
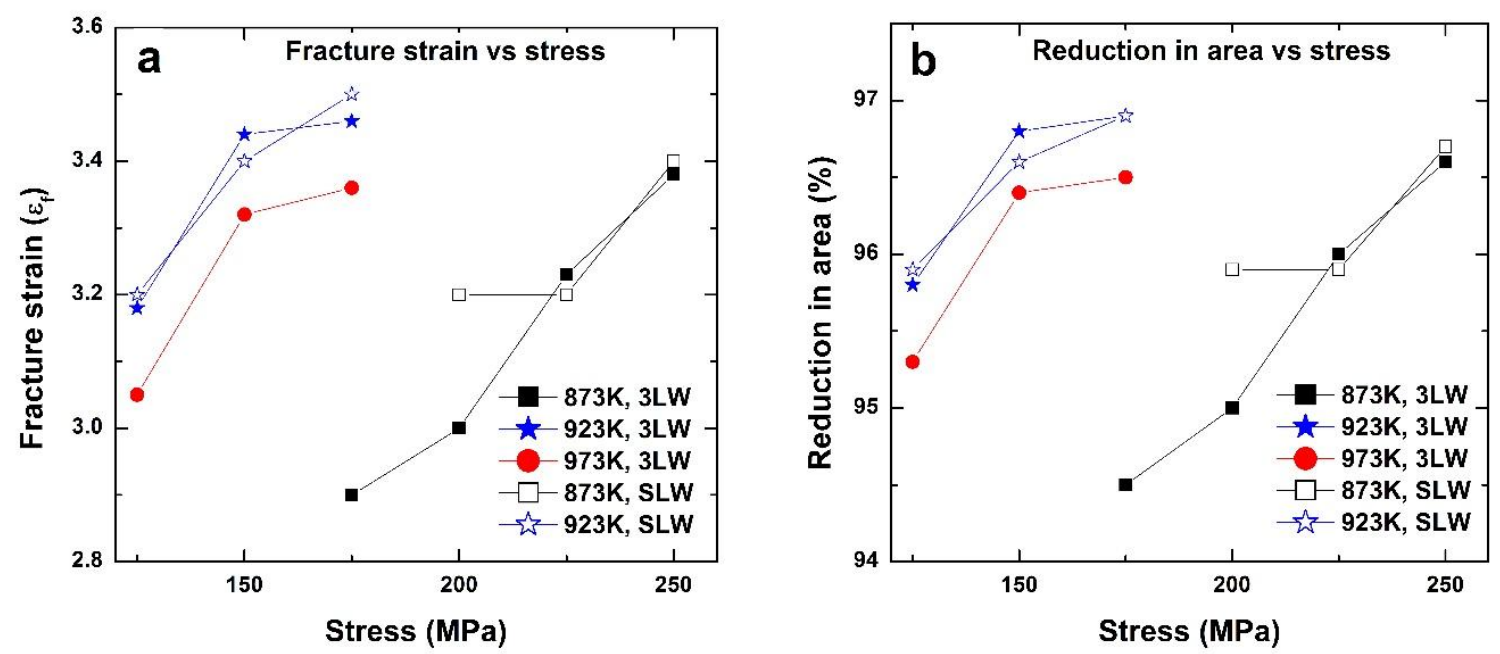

Figure 9 Plot of fracture strain (a) and reduction in area (b) with stress for 3LW and SLW. 


\subsection{Creep deformation mechanism of weld joints}

Figure 10 compares creep of $3 \mathrm{LW}$ as a function of time for the same stress (Figure 10a) and the same temperature (Figure 10b). The creep rate increased and rupture time decreased with increasing applied stress and temperature. The Norton power law was used to analyze the stress dependence of the minimum creep rate.
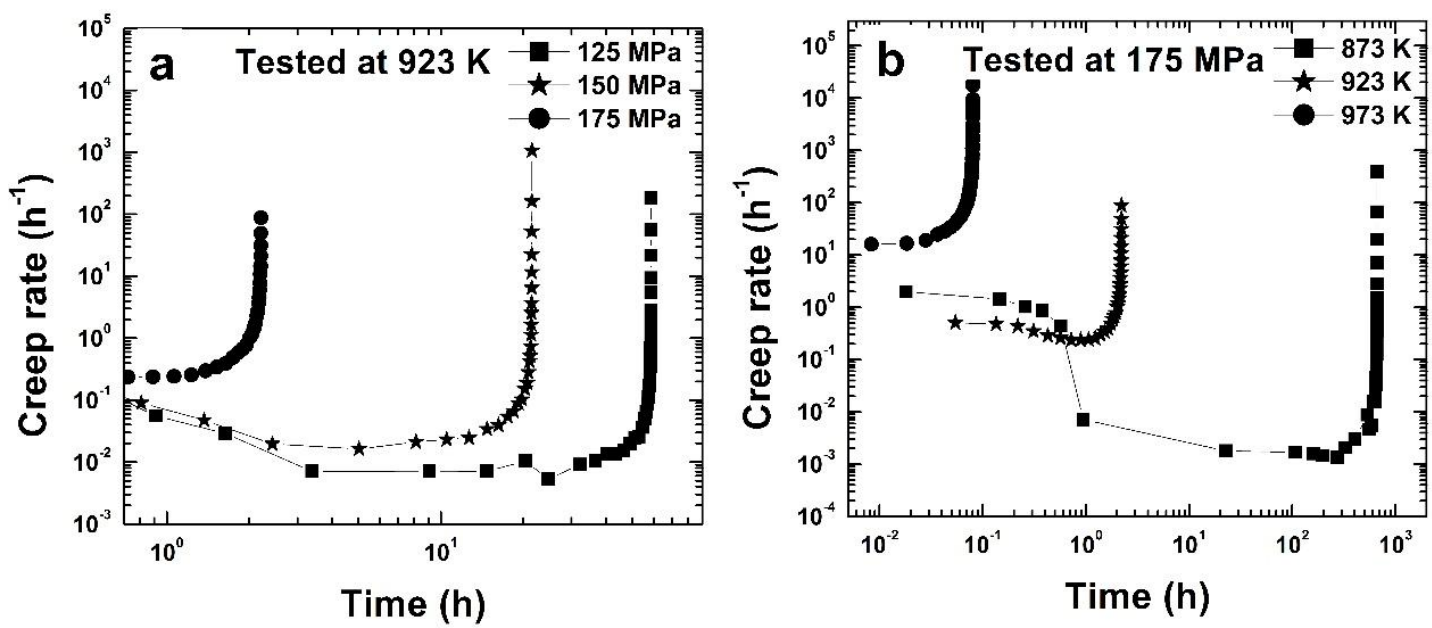

Figure 10 Variation in creep rates as a function of (a) stress and (b) temperature for three layer welds.
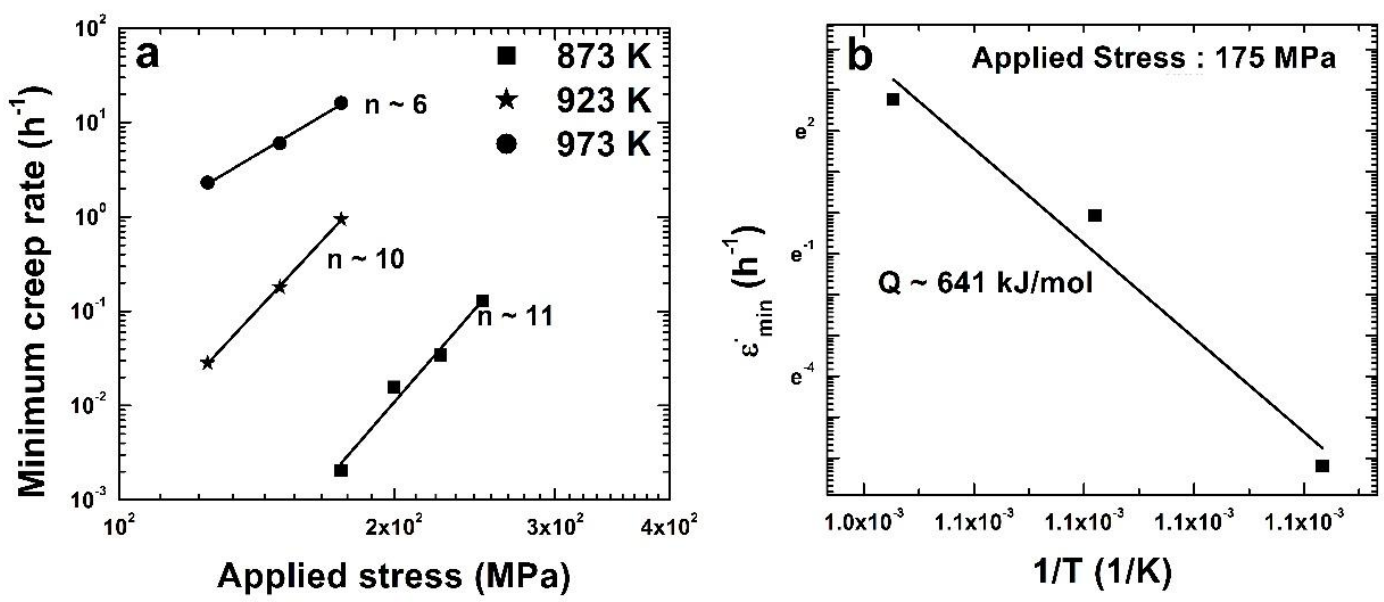

Figure 11 (a) log-log plot between minimum creep rate vs applied stress (b) plot between minimum creep rate vs inverse of temperature for apparent activation energy calculation for $3 \mathrm{LW}$. 
Figure 11a shows a double logarithmic plot of minimum creep rate and stress. The slope of logarithmic plot between minimum creep rate and stress give the stress exponent $(n)$. The stress exponent $(n)$ values obtained for 873,923 , and $973 \mathrm{~K}$ are approximately 11, 10, and 6 respectively. The apparent activation energy of about 641 $\mathrm{kJ} / \mathrm{mol}$ is obtained for the tests performed at $175 \mathrm{MPa}$ as shown in Figure 11b. Similarly, high values of stress exponent and activation energy were reported previously in a number of studies. Shrestha et al. [23] reported the stress exponent of 11 at high stress regime with an activation energy of $510 \mathrm{~kJ} / \mathrm{mol}$ for the monolithic Grade 91 specimen. Choudhary et al. [25] reported activation energy of $621 \mathrm{~kJ} / \mathrm{mol}$ and stress exponent of 12 at test temperature range of $823 \mathrm{~K}$ to $873 \mathrm{~K}$. In both of their works, decreased stress exponent was observed with increased temperature and these studies were carried out on un-welded creep samples. A high stress exponent of 22 and an activation energy of 1,117 $\mathrm{kJ} / \mathrm{mol}$ was reported by Anderson et al. [26] for samples tested at high stress (220 to 240 $\mathrm{MPa}$ at $823-923 \mathrm{~K}$ ) regime. They indicated that the stress exponent and activation energy shift to lower values at low stress and high temperature regime.

The applied stress in the present work is more than $100 \mathrm{MPa}$ which is intermediate to high stress regimes. Therefore, high values of stress exponent and activation energy obtained in the present work are also in agreement with reported work in literature. A decreasing stress exponent value is observed with increasing temperature. A lower value of stress exponent at high temperature could correspond to dissolution of precipitates at elevated temperature which is also in agreement with the previously reported works. It is noted that higher stress exponent and activation energy more than the normal values require incorporation of threshold stress which arises due to the 
interruption of dislocation motion by fine particles. In Grade 91 steels, MX type particles can help in creating this kind of effect. Different approaches were taken to calculate the threshold stress as reported in literature [23,27-29]. In the present work, linear extrapolation method as adopted by Shrestha et al. [23], Mishra et al. [29], and Huang and Langdon [30] is used to calculate the threshold stress.

Minimum creep rate raised to the power of the inverse stress exponent versus modulus compensated stress is plotted with possible stress exponent is shown in Figure 12. The stress exponent was varied from 3 to 6 to identify the operating creep mechanism between viscous glide $(n=3)$ and dislocation climb $(n=5)$. Figure 12a and Figure 12b show the plots when stress exponents were chosen as 3 and 5 , respectively. At $n=3$, the correlation coefficient of $0.96,0.97$, and 0.98 were obtained at 873,923 , and $973 \mathrm{~K}$, respectively. At $n=5$, the correlation coefficient of $0.98,0.99$, and 0.99 were obtained at 873, 923 and $973 \mathrm{~K}$, respectively. A better fit was found for a stress exponent of 5 than 3, and stress exponents less than 3 resulted in a poor fit. The threshold stresses obtained from the linear extrapolation at 873,923 , and $973 \mathrm{~K}$ for $n=3$ were $150.1,104.4$, and 71.5 MPa, respectively. Similarly, the threshold stresses obtained from the linear extrapolation at 873,923 , and $973 \mathrm{~K}$ for $n=5$, were $113.3,76.8$, and $20.6 \mathrm{MPa}$, respectively. The obtained threshold stresses were incorporated in double logarithmic plot of minimum creep rate and stress as shown in Figure 13. After incorporating the threshold stress, in both the cases, the stress exponent obtained is close to the values associated with the threshold stress values. 

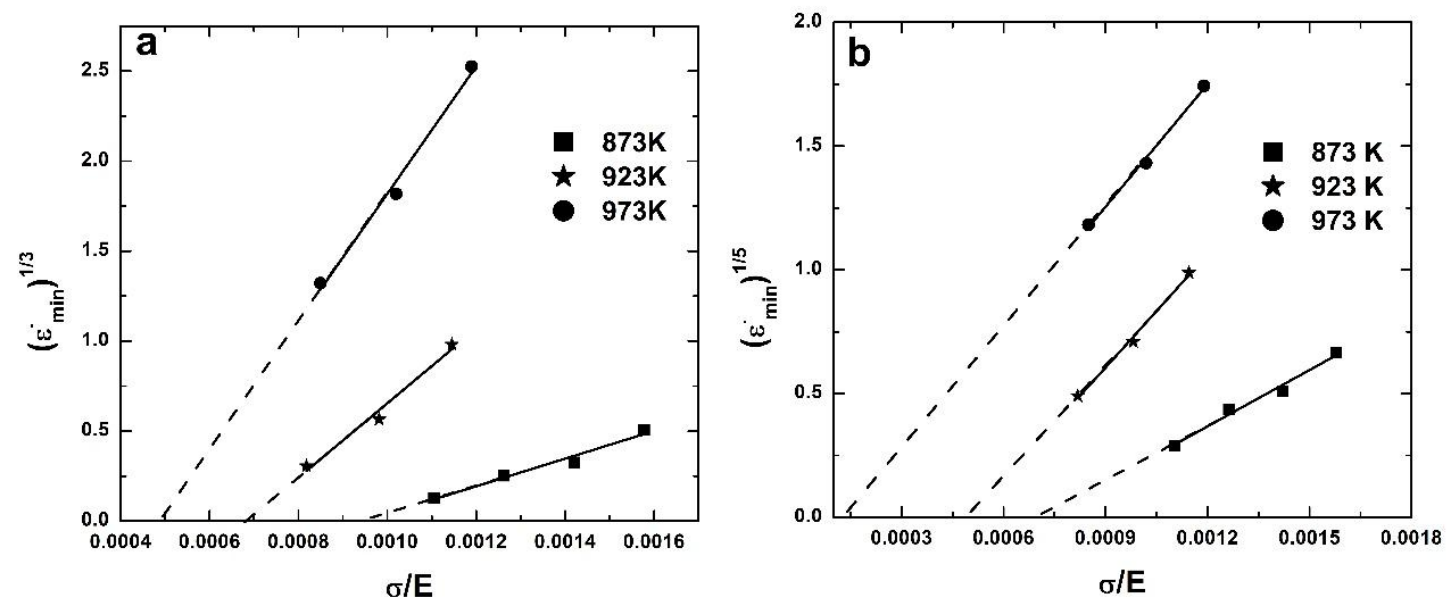

Figure 12 Linear extrapolation plot for threshold stress calculation for (a) viscous glide $(n=3)$ and (b) dislocation climb $(n=5)$.
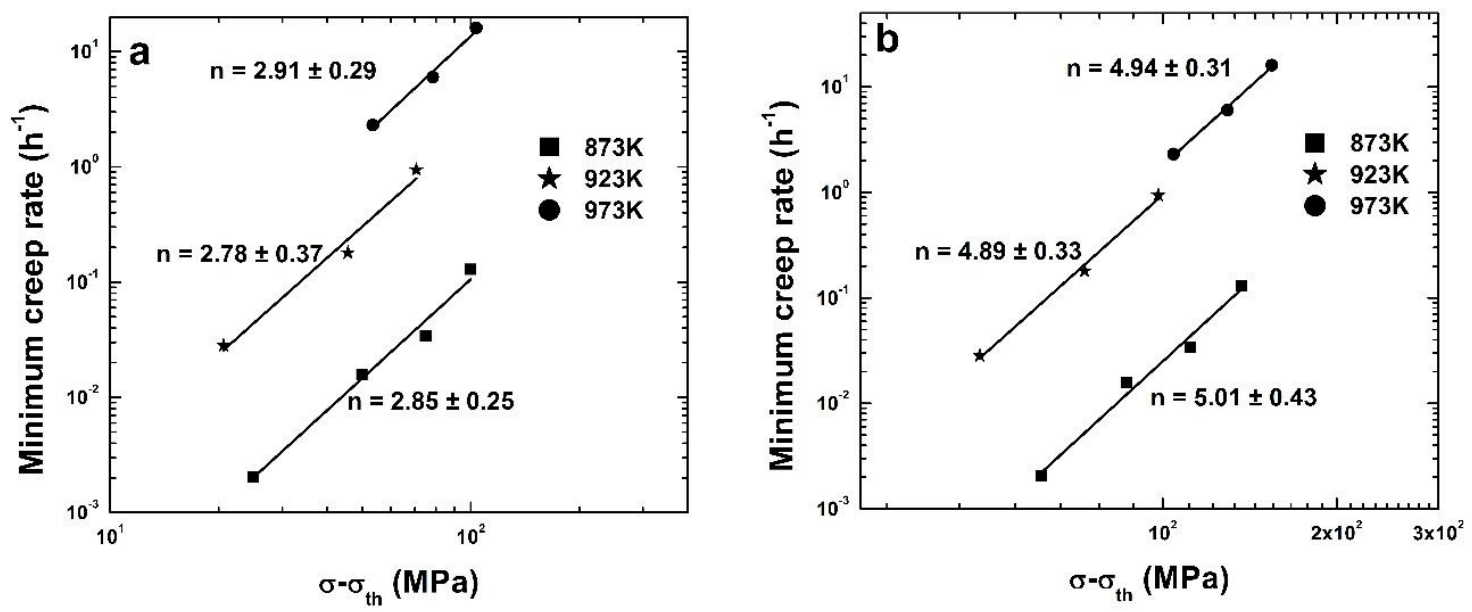

Figure 13 Double logarithmic plots between minimum creep rate vs. effective stress for true stress exponent assuming (a) viscous glide and (b) dislocation climb as a creep mechanism.

To calculate the true activation energy, minimum creep rate was plotted against modulus compensated effective stress for each temperature. From the plot, the corresponding creep rates were deduced for each temperature at constant modulus 
compensated effective stress. The obtained creep rates were plotted against inverse temperature for both cases shown in Figure 14. A true Activation energy of $289 \mathrm{~kJ} / \mathrm{mol}$ is obtained assuming stress exponent of 3 at $4.0 \times 10^{-4}$ modulus compensated effective stress as shown in Figure 14a. Similarly, true Activation energy of $290 \mathrm{~kJ} / \mathrm{mol}$ is obtained assuming stress exponent of 5 at $8.2 \times 10^{-4}$ modulus compensated effective stress as shown in Figure 14b. The obtained activation energy is reduced from the high value of 621 $\mathrm{kJ} / \mathrm{mol}$ to $290 \mathrm{~kJ} / \mathrm{mol}$ which is close to activation energy of lattice diffusion in $\alpha$-iron. Afterward, all the minimum creep rates obtained for each temperature were normalized with lattice diffusion $\left(\varepsilon_{m i n}^{\cdot} k T / D E b\right)$ and plotted against modulus compensated effective stress $\left(\left(\sigma-\sigma_{\text {th }}\right) / \mathrm{E}\right)$ to identify the operating creep mechanism between viscous glide $(n=3)$ and dislocation climb $(\mathrm{n}>4)$.

$\mathrm{D}$ is the diffusivity described by the following relation, $D=D_{o} \exp \left(-\frac{Q_{\text {apt }}}{R T}\right)$, where $\mathrm{Q}_{\text {apt }}$ is the apparent activation energy obtained from linear extrapolation for $n=3$ and $n=5, D_{0}$ (diffusivity constant) is equal to $1.9 \times 10^{-4} \mathrm{~m}^{2} \mathrm{~s}^{-1}$ [27], $R$ is the gas constant and $\mathrm{T}$ is the temperature in $\mathrm{K}$. Burgers vector of $2.8 \times 10^{-10} \mathrm{~m} \mathrm{[27]} \mathrm{and} E_{o}$ (shear modulus) of $223 \mathrm{GPa}$ was used. Figure 15a and Figure 15b are the normalized plots for viscous glide $(n=3)$ and dislocation climb $(n=5)$, respectively. It can be seen that all the data fall reasonably close to $2.8(\sim 3)$ when true activation energy and threshold stress were taken assuming viscous glide as creep mechanism $(n=3)$ as shown in Figure 15a. On the other hand, a single stress exponent of 3.98 is obtained when true activation energy and threshold stress was incorporated assuming dislocation climb as a creep mechanism $(n=$ 5) as shown in Figure 15b. Quite a large difference in stress exponent (3.98) from the assumed stress exponent (5) is found in the latter case. Assuming viscous glide as creep 
mechanism, all the data merged reasonably well close to assumed stress exponent of $\sim 3$. Therefore, it could be concluded that creep deformation mechanism of weld transition joint studied in the present work at high stress regime is viscous glide. This is in contradiction with the reported creep mechanism of $9 \mathrm{Cr}-1 \mathrm{Mo}$ steel which is predominantly accepted as dislocation climb [23,27]. However, this difference may be explained by considering the structural changes induced during creep exposure between a parent metal and dissimilar metal joints.
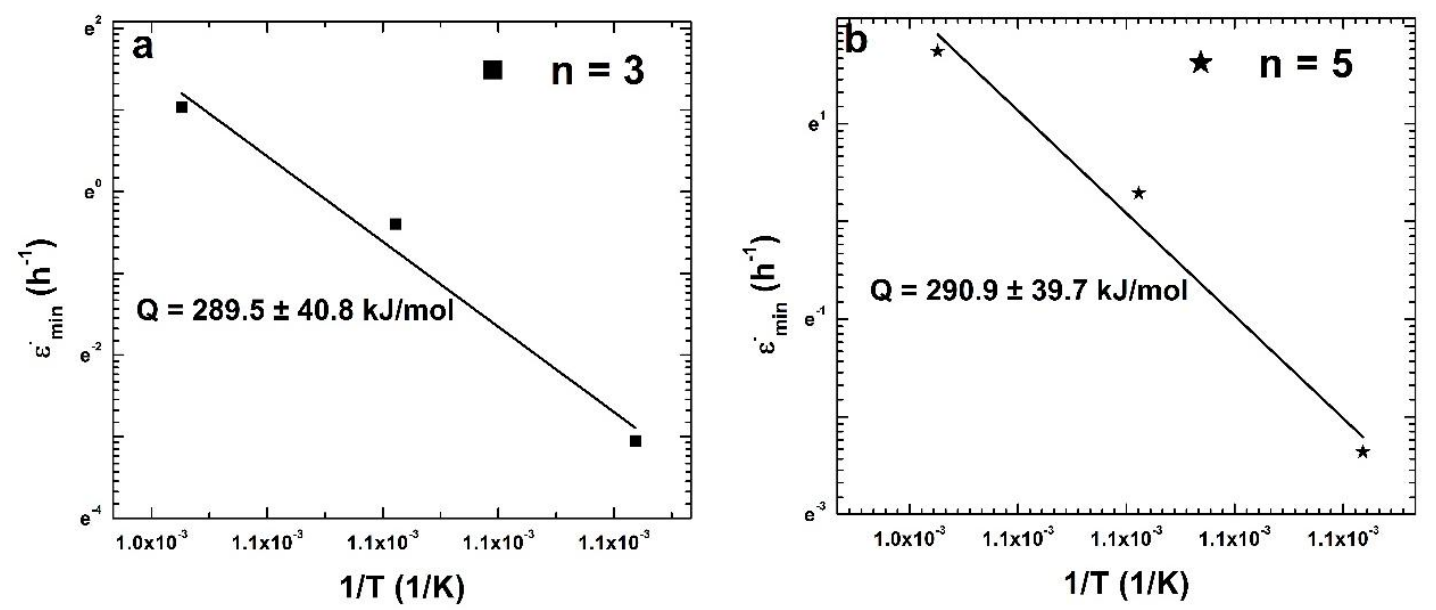

Figure 14 Minimum creep rate vs inverse temperature plot for true activation energy assuming (a) viscous glide and (b) dislocation climb.
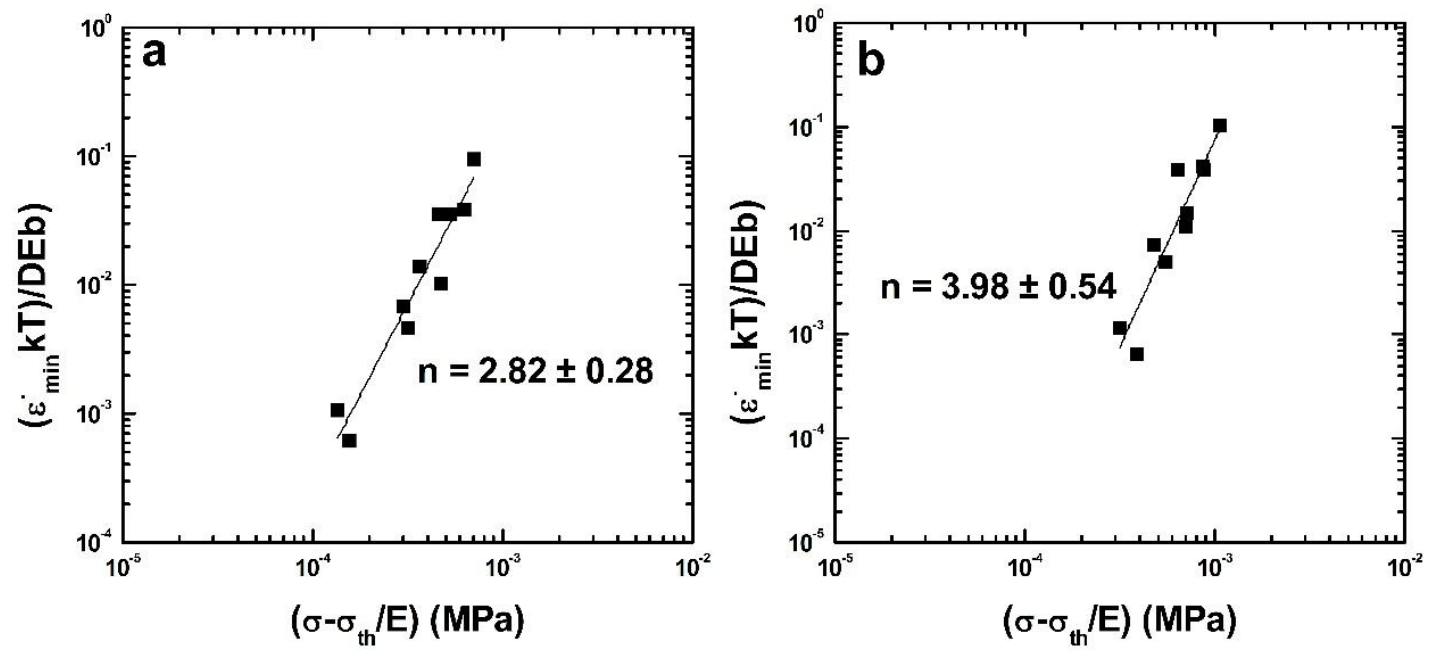
Figure 15 Plot between diffusion compensated minimum creep rate vs modulus compensated effective stress (a) for viscous glide $(n=3)$ and (b) for dislocation climb (n $=5$ ).

As shown in Figure 7, all the failures were located at the soft zone in the HAZ of P91, which was also true for the other crept (3LW) specimen shown in Figure 16 tested at $873 \mathrm{~K} / 175 \mathrm{MPa}$ (rupture time $652 \mathrm{~h}$ ) near the weld interface and fracture tip. Figure 16a reveals a typical lath martensitic structure with a hardness of $280 \mathrm{HV}$ near the weld interface. On the other hand, the microstructure near fracture tip shows a loss of martensite as shown in Figure 16b, in conformity with hardness value of $205 \mathrm{HV}$. It can also be seen from Figure 6 that the soft zone width which exists in the HAZ of P91 extends over time towards FGHAZ as compared to the PWHT sample. The formation and extension of the soft zone (loss of lath martensite) is facilitated by diffusion of carbon from lath martensite which will precipitate out in the form of carbides at the grain boundaries. Therefore, the viscous glide creep mechanism in these weld joints could be due to diffusion of carbon atoms. The activation energy of carbon diffusion in Fe and/or $\mathrm{Ni}$ is quite small. It is proposed that as carbon atoms diffuse, they drag the pinned dislocations with them and impose solute drag based viscous glide. It is reported in the literature that when stress exponent $n=3$, dislocation glide is controlled by the rate of migration of solute atoms that are attached to moving dislocations [31,32]. Therefore, the controlling creep deformation mechanism of the weld joints studied in the present work is proposed to be viscous glide due to the diffusion of carbon. 

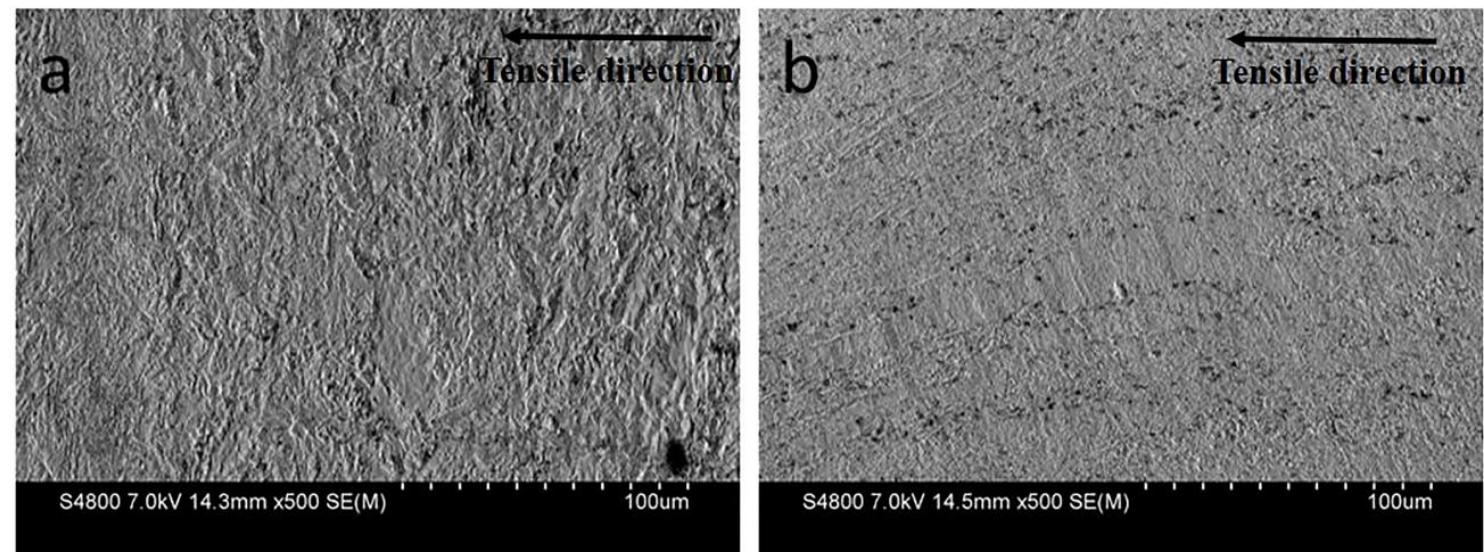

Figure 16 Microstructure of crept sample (3LW) tested at $873 \mathrm{~K}$ and $175 \mathrm{MPa}$ (Rupture time $=652$ hours) (a) at the interface of $9 \mathrm{Cr}-1 \mathrm{Mo}$ steel and Inconel 625 (b) at fracture tip.

\subsection{Analysis of creep rupture data}

The time to reach the onset of tertiary stage is related to rupture time by the following relationship.

$$
t_{r t}^{m}=C t_{o t s}
$$

where $t_{r t}$ is the rupture time, $t_{\text {ots }}$ is the onset of tertiary stage, and $C$ is a constant. Figure 17 shows the plot between rupture time and onset of the tertiary stage. All the data fit well in a straight line with a slope of $\sim 1.0$. From the deduced constant value, $t_{\text {ots }}$ is equal to 0.44 fraction of $t_{r t}$ where exponent ' $m$ ' is almost equal to 1 . This indicates that the time spent in tertiary stage is quite large and contribution from secondary and primary creep stage is small. This also suggests that contribution to the creep strain from secondary and primary is small as compared to tertiary stage and maximum ductility was derived from the tertiary stage of the creep. A low value of C (0.28) was also obtained in parent 9Cr-1Mo steel [25]. 


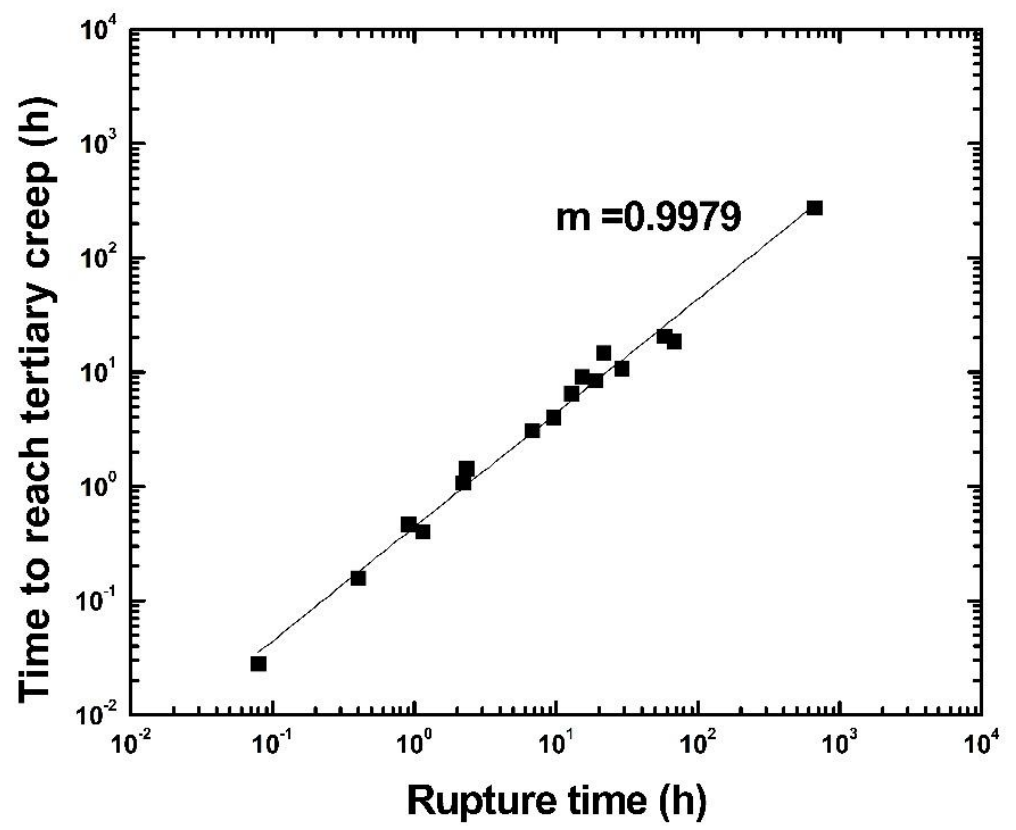

Figure 17 Plot between time to reach tertiary creep vs rupture time for three layer weld and single layer welds at 873,923 , and $973 \mathrm{~K}$.

The minimum creep rate and rupture time relationship is given by MonkmanGrant equation [33] and expressed as follows

$$
\dot{\varepsilon}_{m}^{m \prime} t_{r t}=C_{M G}
$$

where $C_{M G}$ is the Monkman-Grant constant, $t_{r t}$ the time to rupture, and $\dot{\varepsilon}_{m}$ the minimum creep rate. $C_{M G}$ and $m^{\prime}$ are the constants and independent of testing temperature, stress, chemical composition and heat treatment of a particular alloy [33]. Figure 18a is a loglog plot between rupture time and minimum creep rate. All of the data fall close to a straight line with a slope $\left(m^{\prime}\right)$ of 0.92 . The Monkman-Grant constant $\left(C_{M G}\right)$ is quite high as compared to 0.036 [25], and 0.04 [24] reported for 9Cr-1Mo steel.

However, variation in intercept values are very common in metallic alloys, such high constant values were also included in Monkman-Grant work [33]. The slope value obtained in this study is close to $0.92(\sim 1.0)$, such values are indicated in studies reported 
by Monkman-Grant [33], Choudhary et al. [25] and Shrestha et al. [24]. It is also mentioned that $m^{\prime}$ value close to 1 is better for good prediction. Therefore, the obtained relationship between rupture time and minimum creep rate can be used for the prediction of rupture time.
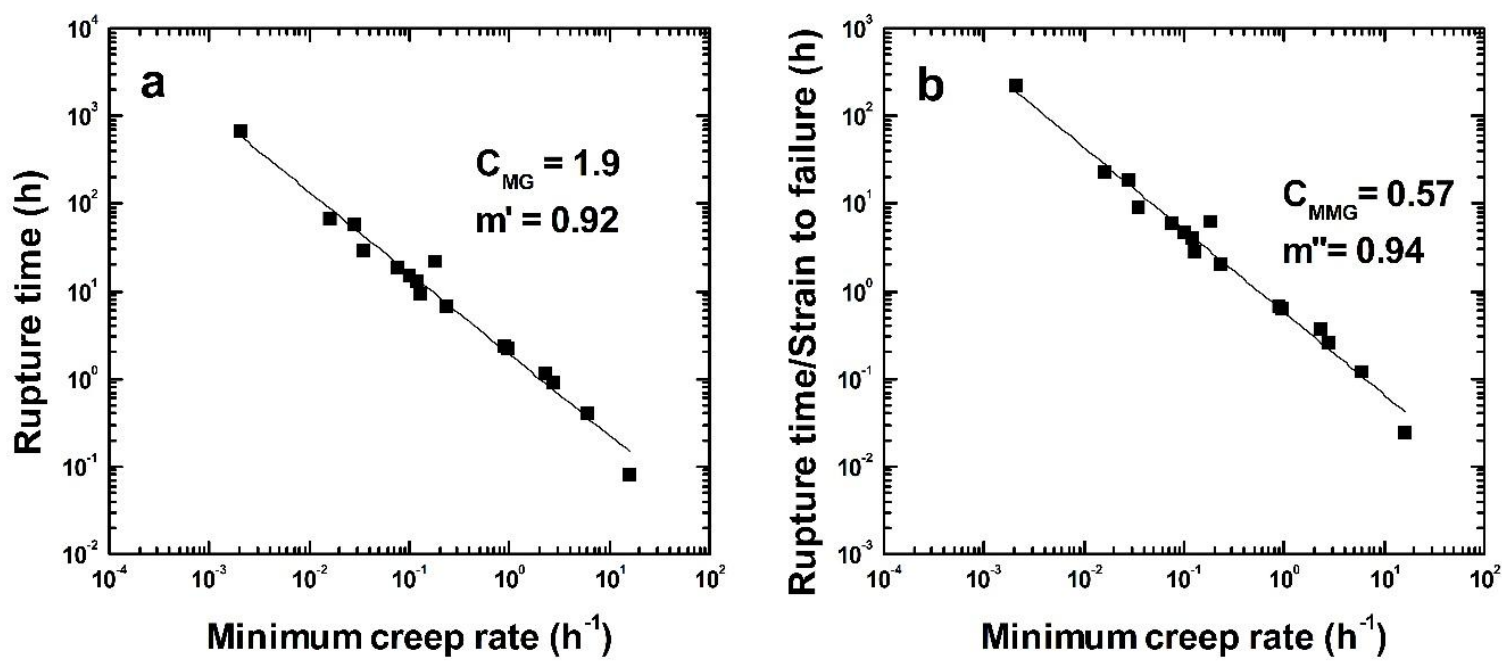

Figure 18 Plots of rupture time vs minimum creep rate showing Monkman-Grant relation

(b) plot between ratio of rupture time to strain to failure and minimum creep rate for Modified Monkman-Grant relation.

Dobes and Milicka [34] proposed a Modified Monkman-Grant relation for metallic alloys which incorporates true fracture strain in the relationship given by following relation:

$$
\dot{\varepsilon}_{m}^{m \prime \prime} \frac{t_{r t}}{\varepsilon_{f}}=C_{M M G}
$$

where $\varepsilon_{f}$ is the strain to fracture and $C_{M M G}$ and $m$ " are the Modified Monkman Grant constants independent of stress and temperature. Figure 18b is a log-log plot between rupture time/strain to failure and minimum creep rate. A slope $\left(m^{\prime \prime}\right)$ of 0.94 and constant value $\left(C_{M M G}\right)$ of 0.57 was obtained for weld joints as shown in Figure 18b. From the 
obtained constant $\left(C_{M M G}\right)$ value, a creep damage tolerance factor $(\lambda)$ was evaluated. A creep damage tolerance factor $(\lambda)$ is expressed as inverse of $\left(C_{M M G}\right)[35,36]$ and used to find out the operating rupture mode. Typically, the value of $\lambda$ ranges from 1 to 20 for engineering alloys [24,36]. There are many ways creep damage can occur such as external necking, internal necking due to cavity formation and growth, oxidation, and microstructural degradation (coarsening of particles) [25,36]. Each creep damage mechanism acting on material results in corresponding value of $\lambda$.

For example, when $\lambda=1$, creep damage occurs in a brittle fracture mode without significant plastic deformation and have very low creep strain. $\lambda$ values in between 1.5 to 2.5 indicates that damage is facilitated by growth of cavities due to combined effect of power law and diffusional creep [36]. A higher value of $\lambda$ (more than 5) indicates that material can withstand strain concentration without local cracking and microstructural degradation as the dominant creep damage mechanism. For the plain P91 steel, higher value of $\lambda$ close to 5 is reported in literature [24,25]. In the present work, intermediate value of $\lambda$ is obtained which is 1.75 for weld joints. This value falls in the range of 1.5 to 2.5 indicating that the creep damage mechanism is due to growth of cavities from combined effect of power law and diffusion creep. The presence of neighboring material especially at the interface of P91 steel assists in diffusion process due to different chemistry of a material. Thus, the $\lambda$ value changed from 5 for plain P91 steel to 1.75 for weld joints. A creep damage tolerance factor $(\lambda)$ of 1.75 obtained in the present work is also in conformity with the fractography results as shown in Figure 8. The entire fractured surface reveals the presence of creep cavities and voids. Therefore, the creep damage mechanism in weld joints in the present work is attributed to growth of cavities. 


\section{Conclusions}

Weld transition joints between P91 steel and AISI 304 consisting of three Inconel interlayers (P91/IN625/IN600/IN800H/AISI304) showed better rupture life as compared to single interlayer welds (P91/IN600/AISI304). The increased rupture life is correlated to gradual transition in coefficient of thermal expansion between P91 steel and AISI 304 stainless steel. A stress exponent $(n)$ of 3 was obtained suggesting creep deformation mechanism as viscous glide due to solute drag effect. Transgranular mode of fracture was observed in all crept samples. Creep damage tolerance factor $(\lambda)$ of 1.75 was obtained which indicates the damage mechanism is due to cavity growth by the combined effect of power law and diffusion creep.

\section{Acknowledgement}

The authors gratefully acknowledge the financial help rendered by National Science Foundation, USA (grant no. 1234079) in supporting this work.

\section{References}

[1] K. Burnard, J. Julie, B. Li, G. Brunet, F.E. Bauer, Emissions Reduction through Upgrade of Coal-Fired Power Plants, France, 2014. doi:https://www.iea.org/publications/freepublications/publication/PartnerCountryS eriesEmissionsReductionthroughUpgradeofCoalFiredPowerPlants.pdf.

[2] R. Viswanathan, R. Purgert, S. Goodstine, J. Tanzosh, G. Stanko, J.P. Shingledecker, B. Vitalis, R. Power, U . S . Program on Materials Technology for Ultrasupercritical Coal-Fired Boilers, in: Adv. Mater. Technol. Foss. Power Plants Proc. 5th Int. Coference, 2008. doi:http://www.asminternational.org/documents/10192/1849770/05226G_Sample. pdf.

[3] R. Viswanathan, A.F. Armor, G. Booras, A critical look at supercritical plants, Power Mag. (2004) 42-49. 
[4] J.C. Vaillant, B. Vandenberghe, B. Hahn, H. Heuser, C. Jochum, T/P23, 24, 911 and 92: New grades for advanced coal-fired power plants-Properties and experience, Int. J. Press. Vessel. Pip. 85 (2008) 38-46. doi:10.1016/j.ijpvp.2007.06.011.

[5] P.J. Ennis, a. Czyrska-Filemonowicz, Recent advances in creep-resistant steels for power plant applications, Sadhana. 28 (2003) 709-730. doi:10.1007/BF02706455.

[6] C.D. Lundin, Dissimilar Metal Welds - Transition Joints Literature Review, Weld. J. (1982) 58s-63s.

[7] K. Laha, K.S. Chandravathi, P. Parameswaran, S. Goyal, M.D. Mathew, A comparison of creep rupture strength of ferritic/austenitic dissimilar weld joints of different grades of Cr-Mo ferritic steels, Metall. Mater. Trans. A. 43 (2012) 11741186. doi:10.1007/s11661-011-0957-8.

[8] J.N. Dupont, R.E. Mizia, Review of Dissimilar Metal Welding for the NGNP Helical-Coil Steam Generator, 2010. doi:INL/EXT-10-18459.

[9] A.K. Bhaduri, Transition metal joints for steam generatore-An overview, Int. J. Press. Vessel. Pip. 58 (1994) 251-265.

[10] J.M. Race, Carbon Diffusion Across Dissimilar Steel Welds, Thesis. 1992.

[11] Y.Y. You, R.K. Shiue, R.H. Shiue, C. Chen, The study of carbon migration in dissimilar welding of the modified 9Cr-1Mo steel, J. Mater. Sci. Lett. 20 (2001) 1429-1432. doi:10.1023/A:1011616232396.

[12] J.F. Eckel, Diffusion Across Dissimilar Metal Joints, Weld. J. 43 (1964) 170s178 s.

[13] S. Kihara, J.B. Newkirk, A. Ohtomo, Y. Saiga, Morphology changes of carbide during creep and their effects on the creep properties of inconel 617 at $1000 \mathrm{C}$, Metall. Mater. Trans. A. 11 (1980) 1019-1031.

[14] J.C. Lippold, S.D. Kiser, J.N. DuPont, Welding Metallurgy and Weldability of Nckel base Alloys, John Wiler Publication, 2009.

[15] J.A. Williams, Residual stresses in austenitic-ferritic transition joints fabricated with austenitic weld metal, High Temp. Technol. 2 (1984) 135-140.

[16] H.Y. Lee, S.H. Lee, J.B. Kim, J.H. Lee, Creep-fatigue damage for a structure with dissimilar metal welds of modified 9Cr-1Mo steel and 316L stainless steel, Int. J. Fatigue. 29 (2007) 1868-1879. doi:10.1016/j.ijfatigue.2007.02.009.

[17] J.D. Parker, G.C. Stratford, Characterisation of microstructures in nickel based transition joints, J. Mater. Sci. 35 (2000) 4099-4107. doi:10.1023/A:1004846607046. 
[18] Y. Gong, J. Cao, L.N. Ji, C. Yang, C. Yao, Z.G. Yang, J. Wang, X.M. Luo, F.M. Gu, A.F. Qi, S.Y. Ye, Z.F. Hu, Assessment of creep rupture properties for dissimilar steels welded joints between T92 and HR3C, Fatigue Fract. Eng. Mater. Struct. 34 (2011) 83-96. doi:10.1111/j.1460-2695.2010.01496.x.

[19] M. Yamazaki, T. Watanabe, H. Hongo, M. Tabuchi, Creep Rupture Properties of Welded Joints of Heat Resistant Steels, Int. Conf. Power Eng. (2007) 1144-1148. doi:10.1299/jpes.2.1140.

[20] J. An, H. Jing, G. Xiao, L. Zhao, L. Xu, Analysis of the creep behavior of p92 steel welded joint, J. Mater. Eng. Perform. 20 (2011) 1474-1480. doi:10.1007/s11665010-9779-x.

[21] H. Hänninen, P. Aaltonen, A. Brederholm, U. Ehrnsteń, H. Gripenberg, A. Toivonen, J. Pitkan̈en, I. Virkkunen, Dissimilar metal weld joints and their performance in nuclear power plant and oil refinery conditions, VTT Tied. - Res. Notes 2347. (2006) 3-208.

[22] F. Abe, Precipitate design for creep strengthening of $9 \% \mathrm{Cr}$ tempered martensitic steel for ultra-supercritical power plants, Sci. Technol. Adv. Mater. 9 (2008) 13002. doi:10.1088/1468-6996/9/1/013002.

[23] T. Shrestha, M. Basirat, I. Charit, G.P. Potirniche, K.K. Rink, U. Sahaym, Creep deformation mechanisms in modified 9Cr-1Mo steel, J. Nucl. Mater. 423 (2012) 110-119. doi:10.1016/j.jnucmat.2012.01.005.

[24] T. Shrestha, M. Basirat, I. Charit, G.P. Potirniche, K.K. Rink, Creep rupture behavior of Grade 91 steel, Mater. Sci. Eng. A. 565 (2013) 382-391. doi:10.1016/j.msea.2012.12.031.

[25] B.K. Choudhary, E. Isaac Samuel, Creep behaviour of modified 9Cr-1Mo ferritic steel, J. Nucl. Mater. 412 (2011) 82-89. doi:10.1016/j.jnucmat.2011.02.024.

[26] P. Anderson, T. Bellgardt, F.L. Jones, Creep deformation in a modified 9Cr-1Mo steel_2003, Mater. Sci. Technol. 19 (2003) 207-213.

[27] B. Ule, a. Nagode, A model based creep equation for $9 \mathrm{Cr}-1 \mathrm{Mo}-0 \cdot 2 \mathrm{~V}$ (P91 type) steel, Mater. Sci. Technol. 23 (2007) 1367-1374. doi:10.1179/174328407X161187.

[28] S. Spigarelli, E. Cerri, P. Bianchi, E. Evangelisa, Interpretation of creep behaviour of a $9 \mathrm{Cr}-\mathrm{Mo}-\mathrm{Nb}-\mathrm{V}-\mathrm{N}$ steel using threshold stress concept, Mater. Sci. Technol. 15 (1999) 1433-1440.

[29] R.S. Mishra, T.R. Bieler, A.K. Mukherjee, Superplasticity in powder metallurgy aluminum alloys and composites, Acta Metall. Mater. 43 (1995) 877-891. doi:10.1016/0956-7151(94)00323-A. 
[30] Y. Huang, T.G. Langdon, The creep behavior of discontinuously reinforced metalmatrix composites, Jom. 55 (2003) 15-20. doi:10.1007/s11837-003-0187-7.

[31] O.D. Sherby, E.M. Taleff, Influence of grain size, solute atoms and second-phase particles on creep behavior of polycrystalline solids, Mater. Sci. Eng. A. 322 (2002) 89-99. doi:10.1016/S0921-5093(01)01121-2.

[32] G. Graiss, A.F. Abd El-Rehim, Examination of breakdown stress in creep by viscous glide in Al-5.5 at.-\% Mg solid solution alloy at high stress levels, Mater. Sci. Technol. 23 (2007) 1144-1148. doi:10.1179/174328407X226545.

[33] F. Monkman, N. Grant, an Empirical Relationship Between Rupture Life and Minimum Creep Rate in Creep-Rupture Tests, Proc. ASTM. 56 (1956) 593-620.

[34] F. Dobes, K. Milicka, The relation between minimum creep rate and time to fracture, Met. Sci. 10 (1976) 382-384.

[35] F.A. Leckie, D.R. Hayhurst, Constitutive equations for creep rupture, Acta Metall. 25 (1977) 1059-1070.

[36] M.F. Ashby, B.F. Dyson, Advances in Fracture Research, vol 1, 1984. 